\title{
As particularidades da política de proteção social em Cuba
}

\author{
The particularities of social protection policy in Cuba
}

\author{
Thiago Agenor* \\ Lívia Marinho de Moura** \\ Lívia Hernandes Carvalho***
}

\begin{abstract}
Resumo
No que tange ao campo do estudo sobre a política da assistência social ou regimes de bem-estar na América Latina, este trabalho se propõe discorrer sobre os aspectos centrais na materialização do direito as políticas sociais, em especial a assistência social tem destaque de importância para a vida da população cubana. Com a realização da pesquisa bibliográfica e documental, descritas no referencial deste trabalho, e as análises realizadas verifica-se que, em Cuba, as políticas sociais, sobretudo o reconhecimento da Assistência Social ocorre como um direito à proteção social, apesar de ainda existir a necessidade de um amadurecimento a respeito da especificidade da Assistência Social e traços da familiarização no tocante às ações.
\end{abstract}

Palavras-Chave: Proteção social. Assistência social e Cuba.

\begin{abstract}
With regard to the field of study on social assistance policy or welfare regimes in Latin America, this paper proposes to discuss the central aspects in the materialization of the right to social policies, especially social assistance is of importance for the life of the Cuban population. With the completion of bibliographic and documentary research, described in the framework of this work, and the analyzes carried out, it appears that, in Cuba, social policies, especially the recognition of Social Assistance, occurs as a right to social protection, although there is still need for maturity regarding the specificity of Social Assistance and traits of familiarization with regard to actions.
\end{abstract}

Keywords: Social protection. Social assistance and Cuba.

\footnotetext{
* Doutorando em Serviço Social e Política Social pela Universidade Estadual de Londrina - UEL; professor e coordenador do Curso de Serviço Social da Fundação Educacional de Andradina; Colaborador do Núcleo de Estudos e Pesquisas em Seguridade e Assistência Social - NEPSAS (PUC/SP).

** Doutorado em Serviço Social pela UNESP. Assistente Social no Tribunal de Justiça do estado de São Paulo - TJSP e do Instituto Nacional de Seguridade Social (INSS) - Agência de Três Lagoas- MS (em vacância). Docente na Associação de Ensino do Mato Grosso do Sul (AEMS), na cidade de Três Lagoas e na Fundação Educacional de Andradina - Andradina / SP.

*** Doutorado em Serviço Social pela UNESP. Docente do Departamento de Serviço Social da Universidade Federal do Triângulo Mineiro (UFTM).
} 


\section{O Ponto de Partida da Pesquisa}

O presente trabalho tem como objetivo destacar alguns aspectos a respeito da política de proteção social em CUBA, com destaque para aspectos das normativas publicadas no campo da política de assistência social. Partindo do texto intitulado "Tendências latinoamericanas da política social pública no século 21", publicado no ano de 2010 pela revista katálysis, a Profa. Dra. Aldaíza Sposati descreve dois desafios a serem trilhados pelas políticas sociais latino-americanas, quais sejam:

[...] superar suas heranças do século 20, sob a conjuntura do modelo neoliberal, e confrontar as desigualdades sociais e econômicas de forma a garantir a universalidade e a equidade de direitos humanos e sociais, tornando-os alcançáveis para os estratos que permanecem precarizados em suas condições de vida, trabalho e cidadania (SPOSATI, 2011, p. 105).

Por essa razão, observa-se nas produções da área que os países da América Latina, entre os finais dos anos das décadas de 1990 e início dos anos 2000 se propõem a harmonizar a democracia política com crescimento econômico e bem-estar social, propondo novos desafios (LECHNER, 1993) para os três pilares: Família, Mercado e Estado, tornando-os produtos de interação (ESPING-ANDERSEN, 1995). Porém devido as crises cíclicas no mundo, verifica-se os afetos também esses lugares.

Diante desses desafios postos questiona-se como se encontra a realidade cubana? Assim, para realização do presente trabalho, foi realizada pesquisa bibliográfica e documental, com levantamento da produção existente no Brasil a respeito das análises sobre as políticas sociais na América Latina, em especial em Cuba.

A escolha partiu das análises efetuadas por Esping-Andersen (1995), o qual demonstra que o desmonte efetuado nos países comunistas (ou, segundo algumas hipóteses, até mesmo os países considerados socialistas) tem desfeito rapidamente seus sistemas de proteção social, o que motiva a conhecer tal situação, seus impactos na vida da população e do mundo, e o levantamento das dificuldades apresentadas.

O referencial teórico para analisar os aspectos centrais na materialização do direito à Assistência Social latino-americana passa pelos estudos de Esping-Andersen, lan Gough, Franzoni e Sposati, como outros que permitem compreender as particularidades da proteção social na assistência social cubana. 


\title{
Elementos Sócio-Históricos de Cuba
}

A entrada de uma proposta neoliberal no campo das políticas sociais fez que os países subdesenvolvidos ou desenvolvidos criassem formas de atenção social na relação entre Mercado, Família e Estado. Ou seja, "os custos sociais da dependência em relação do mercado são muitos altos, além de implicarem uma clara polarização entre os vencedores e perdedores" (ESPING-ANDERSEN, 1995, p. 74), repercutindo principalmente nos contextos de proteção social tardia ${ }^{1}$ dos países latino-americanos.

Sobre que proteção social ${ }^{2}$ esse artigo pretende discorrer? Entende-se por proteção social o conjunto de ações executadas pelo Estado para toda a população; ocorre que em diversos países latino-americanos a proteção social ocorre através de testes seletivos, nas modalidades de seguros, ou nas palavras de Sposati (2013, p. 658):

\begin{abstract}
Enquanto espécie distinta de política pública, a proteção social transita entre o campo público e o privado como se esse locus intermediário de difícil caracterização de responsabilidades para com a atenção a ser prestada fosse, na sociedade do capital, lugar compatível e aceitável à sua natureza de apoio a trabalhadores que não estão necessariamente em exercício do trabalho. São acolhidas nesse nicho difuso de responsabilidades entidades ou organizações sociais que se apresentem como não lucrativas e/ou de atenção gratuita, e mui raramente como coprodutoras de atenções na condição de direito social.
\end{abstract}

Em grande parte dos "países latino-americanos, as políticas sociais são instaladas de forma fragmentada, setorizada e em geral, com acesso limitado ao operariado urbano, e fortes sinais de branqueamento no acesso a seus benefícios" (SPOSATI, 2011, p. 106).

\section{Elementos sócio-históricos de Cuba: dados geográficos, econômicos e sociais}

\footnotetext{
${ }^{1}$ Nos termos de Sposati $(2002$, p. 2): “[...] caracterizo como regulação social tardia os países nos quais os direitos sociais foram legalmente reconhecidos no último quartel do século XX e cujo reconhecimento legal não significa que estejam sendo efetivados, isto é, podem continuar a ser direitos no papel que não passam nem pelas institucionalidades, nem pelos orçamentos públicos." No caso particular de Cuba, vamos notar a tendência a universalidade na proteção social, porém, ainda com uma série de ações pulverizadas, causando um misto na classificação de seu regime, conforme demonstrado por Esping-Andersen (1999 apud WEHRLE, 2011).

2 De acordo com Castel $(2005$, p. 7), podemos distinguir dois tipos de proteção. A proteção civil que garante as liberdades fundamentais e defende a segurança dos bens e das pessoas no quadro de um Estado de direito. A proteção social "que cobre" contra os principais riscos suscetíveis de acarretar uma degradação da situação dos indivíduos, como a doença, o acidente, a velhice sem recursos, as circunstâncias imprevisíveis da vida que podem culminar em casos extremos, na decadência social.
} 
Para tratar da proteção social nos países da América Latina, em especial em Cuba, é preciso um destaque para as suas particularidades sócio-históricas e político-econômicas, com sua incursão nos direitos humanos e sociais (SPOSATI, 2008).

Cuba localiza-se na América Central e Caribe (subcontinente da América), com uma extensão territorial de $110.861 \mathrm{~km}^{2}$; uma população composta de afro-cubanos $51 \%$, europeus ibéricos $37 \%$, afro-americanos $11 \%$, chineses $1 \%$; tem o idioma espanhol o oficial, a religião: cristianismo 41,9\% (católicos 39,5\%, protestantes 2,4\%), sem filiação 57,9\%, outras 0,2\% e o IDH - Índice de Desenvolvimento Humano: 0,775 (PNUD, 2010).

A economia de Cuba é organizada por produtos: 1) agrícolas: cana-de-açúcar (principal), tabaco, arroz e frutas tropicais (banana, laranja, abacaxi);2) Pecuária: bovinos, equinos, aves e suínos;3) Mineração: níquel, cobre, cromita e cobalto;4) Indústria: alimentícia, bebidas, tabaco (produção de charutos), máquinas e química.

Em relação ao envelhecimento, atualmente, 18,3\% dos 11,1 milhões de habitantes da ilha caribenha têm mais de 60 anos. Em 2030, o número chegará a 30\% - Cuba pode se tornar o país mais envelhecido da América. Um estudo do Escritório Nacional de Estatísticas (ONE) prevê que Cuba, em 2025, terá diminuído sua população em mais de 203 mil pessoas. Nessa mesma data, a idade média dos cubanos passará de 38 para 44 anos (ONE, 1999).

O mesmo documento demonstrou que, em 2035, o número de habitantes terá uma redução de 478.544 dos 11.232.144 existentes em meados de 2011. Prevê-se que Cuba terá 10.753.600 habitantes daqui a 23 anos, com 34\% das pessoas com 60 anos ou mais, enquanto o número de mulheres em idade fértil (15-49 anos) será reduzido em 827.296.

Outra questão é a taxa de desemprego cujos valores médios de tal indicador em Cuba durante o período de 1991a 2017 foi 3.76 percentual, com o mínimo de 1.6 percentual em 2008 e o máximo de 8.3 percentual em 1995, conforme demonstra o próprio gráfico 01 abaixo: 
Gráfico 1 - Taxa de desemprego de Cuba

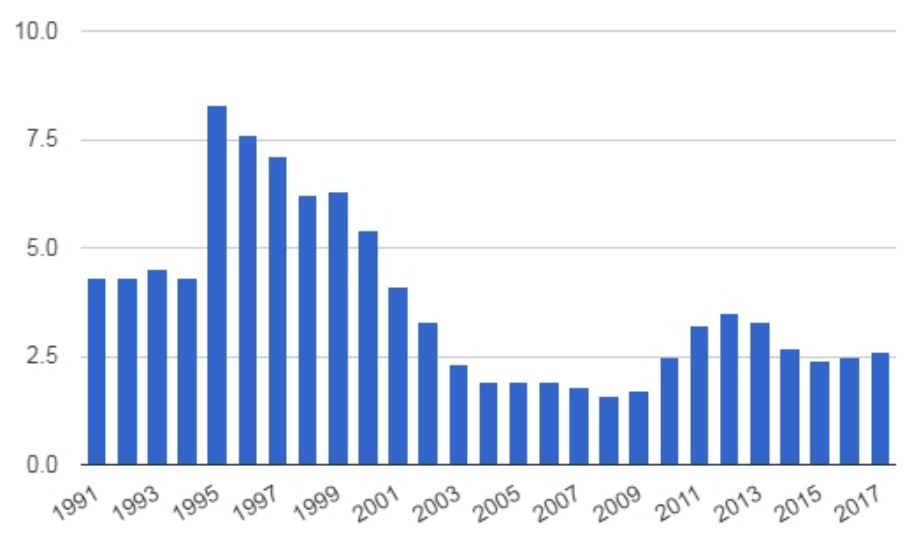

Fonte: The Global Economy ([2018]).

Ademais, o país tem uma renda per capita: $\$ 11,900$ (2016 est.) e um PIB - Produto Interno Bruto de \$132.9 bilhões (2016 est.) ${ }^{3}$. O país está dividido em 15 províncias e um distrito, com 169 municípios.

É preciso destacar que Cuba tem parâmetros de universalidade de suas políticas sociais; isso ocorreu após a chamada revolução cubana, a seguir descreve-se alguns traços desse processo.

\section{A Revolução Cubana}

A revolução cubana de 1959 foi desenvolvida em condições particulares de luta contra o regime militar de Fulgêncio Batista e o neocolonialismo da dominação imperialista norte-americana. Desencadeou-se um processo de transformação social no qual os espaços de participação popular foram fortalecidos com vistas ao exercício pleno dos direitos a todos os cidadãos. Tal processo foi trilhado a partir do levante popular liderado por Fidel Castro Ruz e do aprofundamento como transição socialista nos primeiros dois anos da década de 1960.

A Revolução Cubana instalou um novo poder político e foi capaz de criar novas instituições estatais, com novos planos, restruturação dos serviços públicos e o desempenho das funções governamentais, nas esferas político-legal, administrativa e militar (CARRARO, 2016).

${ }^{3}$ Dados retirados do site: Index Mundi (2019). 
No início do século XXI, após as crises dos anos $1990^{4}$, Cuba sentiu o impacto de vários fatores internacionais que incidiram na política interna, conforme Mesa-Lago (2003, p. 190):

(1) os ataques terroristas de 11 de setembro de 2001 e a guerra no Afeganistão provocaram um declínio drástico do turismo; (2) a recessão que começou em março de 2001 e se agravou em setembro também reduziu as viagens internacionais e cortou as remessas em dólar enviadas por cubanos no exterior; (3) os preços mundiais do níquel caíram $40 \%$ devido à recessão (os preços do açúcar também caíram), que também reduziu a demanda por charutos cubanos; (4) o furacão Michelle atingiu a ilha no dia 4 de novembro, causando danos estimados em 1.866 milhões de pesos, equivalentes a 6,6\% do PIB em 2001; (5) a Rússia fechou a base de vigilância em Lourdes e parou de pagar uma taxa anual de 200 milhões de dólares; (6) o investimento estrangeiro direto despencou em 91\% e graças, em larga medida, à deterioração da economia cubana e à falta de pagamento aos credores, os empréstimos em moeda forte se tornaram mais apertados e caros; e (7) a situação política da Venezuela deteriorou em 2002 e o fornecimento de petróleo foi suspenso. Além disso, a tímida reforma econômica iniciada no começo dos anos noventa e suspensa em 1996 continua paralisada.

A partir desses processos, o governo cubano passou a desenvolver diversas políticas sociais voltadas para a proteção social a população, da qual se destacam-se alguns pontos abaixo:

a) Em setembro de 2013, o Conselho de Ministros, devido ao processo de envelhecimento de Cuba, aprovou o Acordo 47/13 sobre medidas imediatas para um ambicioso programa que inclui a reconstrução, ampliação e equipamento para os centros de idosos. Nessas casas e lares, os idosos recebem atendimento médico de especialistas em Gerontologia e Geriatria, e têm acesso aos serviços de fisioterapeutas, odontologistas e nutricionistas, entre outras especialidades da medicina. O sistema de assistência aos idosos em Cuba conta com benefícios e particularidades que o diferenciam de outros no mundo. Setenta e cinco por cento dos gastos das pessoas que permanecem nas Casas de Avôs correm por conta da Previdência Social. Já nos Lares de Idosos a Previdência cobre 80 por cento das despesas (ARCE, 2017).

b) Em relação à política educacional, encontramos os seguintes dados: o índice de alfabetização de Cuba é o terceiro melhor do mundo, atrás apenas da Geórgia e da Eslováquia, diz o relatório do Programa das Nações Unidas para o Desenvolvimento (PNUD, 2010). As pessoas de 15 a 24 anos tem escolarização mínima de 09 anos; De acordo com a UNESCO, $100 \%$ dos professores estão preparados para exercer as

\footnotetext{
${ }^{4}$ No início de 1990 foi inaugurado um novo momento em CUBA, onde o país enfrentou uma crise econômica desde seu triunfo em 1959. Integrante do bloco socialista durante grande parte da guerra fria, o desaparecimento da URSS (União das Repúblicas Socialistas Soviéticas) e das repúblicas socialistas do Leste Europeu abriu para a ilha caribenha um momento de extremas incertezas, uma vez que o marco de sua integração econômica e política haviam se desmoronado. A situação de isolamento devido à extinção dos aliados internacionais e da hostilidade norte-americana agravou ainda mais a vulnerabilidade do Estado cubano que, além disso, permanecia sob ameaça de invasão externa. Para maiores informações consultar os estudos de Mesa-Lago (2003).
} 
funções na docência; 99,8\% dos matriculados no primário concluíram o ensino; 98,4\% têm ensino secundário; 76,7\% têm o ensino pré-universitário (GANEV, 2013).

c) No campo da saúde, Cuba está no pelotão das 30 nações mais avançadas, com expectativa de vida ao nascer em 77,8\%; a mortalidade infantil era de 4,8 por mil nascidos vivos; concretizou a erradicação da febre amarela, poliomielite, varíola, difteria, caxumba, meningite encefálica, sarampo, coqueluche, rubéola e tétano neonatal. Outro ponto é uma rede de atendimentos médicos, sendo hospitais, clínicas odontológicas, salas de terapia intensiva e entre tantos outros (GANEV, 2013).

\section{Características da Assistência Social em Cuba}

O Ministério do Bem-Estar Social - que durou até 1962 - não alcançou a grande maioria da população e aqueles que não gozavam desses serviços tinham que recorrer ao setor privado ou a entidades de caridade. A partir da revolução, foram aplicadas medidas baseadas no princípio da distribuição equitativa, cujo objetivo era eliminar o desemprego, o analfabetismo e elevar o bem-estar da população. No período entre 1962-1967, as atividades de assistência passam a ser dirigidas e administradas pelas Juntas de Controle, Execução e Inspeção (JUCEI). Em 1972 é criado o Departamento de Assistência Social do Ministério da Saúde Pública e entre 1967 e 1976 são criadas as Comissões do Plano Assistencial em todo o país, com a ajuda das organizações de massa encarregadas de levarem o trabalho de cuidado por todo o país.

Em 1994, o Decreto Lei no 14776, que dispunha sobre a reorganização dos organismos da administração central do Estado, foi criado o Ministério do Trabalho e Segurança Social (MTSS), órgão responsável pelas políticas de seguridade social e assistência social. Qual é o regime da política de Assistência Social de Cuba?

Em todo o continente americano, encontramos vários regimes de segurança social com características particulares. Estes podem ser públicos, privados ou mistos, bem como podem ser diferenciados pelo tipo de benefícios que eles fornecem ${ }^{5}$. A análisea partir das fontes consultados observa-se a realidade de Cuba inserida nos três quadros abaixo:

\footnotetext{
${ }^{5}$ No site Seguridad Social para Todos, observamos o desenvolvimento de ferramentas para consulta dos diferentes sistemas de seguridade social.
} 
Tabela 1 - Regime de velhice, invalidez e de sobrevivência

\begin{tabular}{|c|c|c|c|}
\hline $\begin{array}{c}\text { TIPO E GESTÃO DO } \\
\text { SISTEMA }\end{array}$ & REQUISITOS DE ACESSO & FINANCIAMENTO & $\begin{array}{l}\text { BENEFÍCIOS } \\
\text { PROPOSTOS }\end{array}$ \\
\hline $\begin{array}{l}\text { Regime de seguro social e } \\
\text { regimes especiais para } \\
\text { trabalhadores } \\
\text { independentes, Forças } \\
\text { Armadas Revolucionárias } \\
\text { e o Ministério do Interior, } \\
\text { e membros de } \\
\text { Cooperativas de } \\
\text { Produção Agrícola e } \\
\text { artistas. }\end{array}$ & $\begin{array}{l}\text { Entre } 2009 \text { e } 2016 \text {, a idade } \\
\text { de aposentadoria e a } \\
\text { exigência de anos de } \\
\text { emprego serão } \\
\text { gradualmente aumentadas } \\
\text { para atingir } 65 \text { para } \\
\text { homens e } 60 \text { para } \\
\text { mulheres, com } 30 \text { anos de } \\
\text { serviço. }\end{array}$ & $\begin{array}{l}\text { - Modo de distribuição } \\
\text { anual. Única fonte de } \\
\text { financiamento de } \\
\text { pensões: contribuição de } \\
\text { empresas e organizações } \\
\text { trabalhistas: } 14 \% \text { da folha } \\
\text { de pagamento; } \\
\text { - Trabalhador individual: } \\
10 \% \text { do rendimento } \\
\text { declarado; } \\
\text { - Artistas: } 12 \% ; \\
\text { - O governo financia o } \\
\text { custo do enterro e } \\
\text { qualquer déficit (também } \\
\text { listado como } \\
\text { empregador). }\end{array}$ & $\begin{array}{c}\text { Pensão de velhice; } \\
\text { Pensão de invalidez; } \\
\text { Pensão do sobrevivente. }\end{array}$ \\
\hline $\begin{array}{l}\text { Regime de assistência } \\
\text { social, atua como } \\
\text { complemento à } \\
\text { Previdência Social. }\end{array}$ & $\begin{array}{l}58 \text { anos de idade e } 120 \\
\text { períodos. }\end{array}$ & $\begin{array}{l}\text { Orçamento nacional com } \\
\text { receita proveniente de } \\
\text { receitas gerais. }\end{array}$ & $\begin{array}{c}\text { Benefícios em espécie, } \\
\text { serviços e monetários. } \\
\text { Estes circulam através de } \\
\text { programas: } \\
\text { - Serviços Comunitários } \\
\text { para os Idosos; } \\
\text { - Trabalho social com mães } \\
\text { solteiras; } \\
\text { - Atendimento integral } \\
\text { para crianças com } \\
\text { desvantagem social; } \\
\text { - Assistência social para } \\
\text { pessoas com deficiência. }\end{array}$ \\
\hline
\end{tabular}

Fonte: Elaborado pelo autor com base no site Seguridad Social para Todos.

Quadro 2 - Riscos de trabalho

\begin{tabular}{|c|c|c|}
\hline $\begin{array}{c}\text { TIPO E GESTÃO DO } \\
\text { SISTEMA }\end{array}$ & FINANCIAMENTO & BENEFíCIOS ESPERADOS \\
\hline $\begin{array}{c}\text { Regime de segurança } \\
\text { social. }\end{array}$ & $\begin{array}{c}\text { Estado financia benefícios em serviço e em } \\
\text { espécie. } \\
\text { Organizações trabalhistas financiam pensões. }\end{array}$ & $\begin{array}{c}\text { Benefícios econômicos para acidentes de } \\
\text { trabalho e doenças ocupacionais: } \\
\text { Pensão de invalidez; }\end{array}$ \\
& $\begin{array}{c}\text { Subsídios para incapacidade temporária } \\
\text { e permanente; }\end{array}$ \\
& $\begin{array}{c}\text { Pensão para sobreviventes; } \\
\text { Serviços funerários gratuitos; } \\
\text { Benefícios em espécie: } \\
\text { Aparelhos ortopédicos ou protéticos; } \\
\text { Medicamentos; } \\
\text { Hospitalização. }\end{array}$ \\
\hline
\end{tabular}

Fonte: Elaborado pelo autor com base no site Seguridad Social para Todos. 
Quadro 3 - Benefícios para doença e maternidade

\begin{tabular}{|c|c|c|c|}
\hline $\begin{array}{c}\text { TIPO E GESTÃO DO } \\
\text { SISTEMA }\end{array}$ & $\begin{array}{c}\text { BENEFICIÁRIOS } \\
\text { ALCANÇADOS }\end{array}$ & FINANCIAMENTO & $\begin{array}{c}\text { BENEFÍCIOS } \\
\text { ESPERADOS }\end{array}$ \\
\hline $\begin{array}{c}\text { Regime de segurança } \\
\text { social. }\end{array}$ & Todos os trabalhadores. & $\begin{array}{c}\text { Contribuições de } \\
\text { trabalhadores, empregadores } \\
\text { e governo (isso também cita } \\
\text { como empregador). }\end{array}$ & $\begin{array}{c}\text { Benefícios Monetários: } \\
\text { Por doença; } \\
\text { Para a maternidade; } \\
\text { Subsídio de } \\
\text { amamentação. } \\
\text { Benefícios médicos: } \\
\text { Assistência médica e } \\
\text { odontológica, } \\
\text { maternidade, assistência } \\
\text { neonatal, internação, } \\
\text { medicação durante a } \\
\text { internação, prótese e } \\
\text { reabilitação. }\end{array}$ \\
\hline
\end{tabular}

Fonte: Elaborado pelo autor com base no site Seguridad Social para Todos.

As tabelas mostram como o sistema de segurança social estão construídos em Cuba. Porém, questiona-se: como o país chegou nesta configuração de proteção social?

A estruturação constituinte do Estado Cubano foi instituída apenas em 1976, promulgando direitos, liberdade, justiça e o bem-estar social, com transformações democráticas e iniciativas para a implantação do socialismo. Ela traz importantes direitos sociais ao longo dos seus artigos, como educação, assistência social, moradia e muitos outros. A respeito da Seguridade Social, têm-se no "Art. 47. Mediante o sistema de seguridade social, o Estado garante a proteção adequada ao trabalhador impedido por sua idade, invalidez ou enfermidade. Em caso de morte do trabalhador, garante similar proteção à sua família." (CUBA, 1992, grifo nosso). Fleury (1994, p. 162) afirma ainda que:

Em sua classificação podemos encontrar um primeiro grupo de países pioneiros Chile, Uruguai, Argentina, Cuba e Brasil - onde o sistema de Seguridade Social iniciouse primeiramente, por volta de 1920, e cujos traços principais seriam o elevado nível de estratificação na montagem dos sistemas e a persistente crise fiscal que atravessam há mais de quatro décadas (excetuando-se o caso de Cuba, que teve um desenvolvimento posterior distinto). Nascidos como sistemas fragmentados - cada

\footnotetext{
${ }^{6}$ Cuba, como República, havia tido até a Revolução seis Constituições: a Constituição de Cuáimaro (1869), a Constituição de Baragua (1878), a Constituição de Jimaguayú (1895), a Constituição de La Yaya (1897), a Constituição de 1901 e a Constituição de 1940. Em 1959 foi criada a Lei Fundamental que representava uma versão atualizada da Constituição de 1940, revogando os chamados Estatutos Institucionais da ditadura de Batista. Ainda, é preciso destacar a necessidade de uma nova Constituição foi percebida em função da construção do Poder Popular. Uma Comissão Redatora do Partido e Governo foi organizada com a participação de 20 membros, em 22 de outubro de 1974, sendo dirigida por Blas Roca. Durante os meses de maio e junho de 1975, 6 milhões de cubanos discutiram e aprovaram em mais de 168 mil assembleias, o Anteprojeto da Constituição Socialista (HARNECKER, 1997, p. 123).
} 
instituição protegendo um grupo ocupacional diferente por meio de subsistemas independentes - "este tipo de evolução resultou em uma Seguridade Social estratificada que assumiu uma estrutura piramidal, com relativamente poucos grupos dos segurados protegidos pelos subsistemas privilegiados no ápice e centro e a maioria da população coberta por sistemas mais pobres na base".

No que tange à Assistência Social, embora com nuanças de proteção ou amparo social (CARRO, 2008), no artigo 48 temos a seguinte redação: "O Estado protege, por meio de assistência social, os idosos sem recursos ou abrigo e qualquer pessoa não apta para o trabalho que não tenha familiares em condições de prestar assistência." (CUBA, 1992, grifo nosso).

Como observado, no primeiro momento, a assistência social cubana foi destinada a pessoas não aptas ao trabalho; isso demonstra que a gestão do Estado buscou garantir a proteção a todos os cidadãos, através do Sistema de Previdência Social, abrangendo um regime geral, regimes especiais e um regime de Assistência Social. Em entrevista ao jornal Granma (2017), a vice-diretora-geral do Instituto Nacional de Seguridade Social (INSS) em Cuba, Hayde e Franco Leal, informa:

[...] o último regime protege os idosos sem recursos nem amparo. Também, àquelas pessoas que não são aptas para o trabalho, têm receitas insuficientes para solucionar as necessidades mais determinantes e carecem de familiares em condições de oferecer-Ihes ajuda. Diante destas situações, o Estado apoia com prestações que podem ser monetárias, em serviços ou em alimentos. [...] 0 regime geral é encaminhado à proteção dos trabalhadores nos casos de doenças ou acidente comum ou profissional, maternidade, deficiência, velhice e no caso de morte, aos seus familiares.

Em 1979, foi aprovada a Lei no 24 de Segurança Social, reformulada em 2009 sob a denominação de Lei no 105/08 (CUBA, 2009). A assistência social é apresentada como política complementar à segurança social. Como os demais direitos, a assistência social integra a Política Social concebida como única e de responsabilidade do Estado, a fim de garantir proteção à população em estado de necessidade, conforme estabelece a Lei no 24 .

Com essa nova legislação, a direção da Assistência Social é conduzida pelo Ministério de Trabalho e Previdência Social, o qual conta com uma pequena estrutura de pessoal, sendo os seus serviços descentralizados e executados por pessoal de nível médio (CÉSAR, 2005). 
$\mathrm{Na}$ legislação cubana, as reformulações contribuíram para redefinir os serviços sociais, previstos nos programas e ações de proteção social dirigidos a melhorar a qualidade de vida e a integração de seus beneficiários, conforme art. 106 da Lei 105/08 (CUBA, 2009).

O artigo 112 da referida Lei define os serviços sociais organizados territorialmente, segundo a sua complexidade e especificidade, a saber: (i) serviços sociais comunitários e (ii) serviços sociais institucionais. Ambos de responsabilidade direta do Estado. Entre Brasil e Cuba existem aproximações em relação à regulamentação da assistência social, seja na sua condição de direito, seja na sua composição e/ou complementaridade com a previdência social/segurança social (BORTOLI; COUTO; TELES, 2015). As principais ações são transformadas em serviços, programas e benefícios ${ }^{7}$ :

Nesse sentido, o Estado protege a população que precisa através de um conjunto de benefícios de Assistência Social e programas de serviços sociais. Entre os principais programas sociais desenvolvidos dentro da Assistência Social, estão: Programa Nacional de Serviços Sociais comunitários para o idoso, Assistência Social a Domicílio (ASD), Programa de cuidados para deficientes físicos, Proteção às mães de crianças com deficiências graves, casas de anciãos, mães solteiras com filhos menores sob sua responsabilidade, Casa dos Avós, Creche do Sistema Nacional de Educação, Reparação de moradias, transporte, Serviços Jurídicos, Barbeiro e cabeleireiro, Lavagem de roupas, pagamento a domicílio dos beneficiários da Seguridade Social (ÁLVAREZ GARCÍA; CRUZ, 2009, p. 8).

O acesso aos serviços sociais em Cuba é garantido às famílias dos trabalhadores assalariados ou pensionistas; aos trabalhadores que recebem subsídios por doença ou acidente; aos trabalhadores que atingem a idade mínima para acessar a pensão por idade e não cumprem o requisito de tempo mínimo de serviços; às mães trabalhadoras no período que desfrutem de licença não remunerada para cuidar dos filhos e que estejam em situação de carência econômica; à família de jovens que estejam prestando serviço militar e que constituam o único ou parte do sustento familiar; aos órfãos de um só responsável, pensionistas pela segurança social que chegam aos 17 anos de idade e que se encontram estudando; aos pensionados com renda insuficiente segundo o número de dependentes; à outras pessoas possam requerer a assistência social (BORTOLI; COUTO; TELES, 2015).

\footnotetext{
${ }^{7}$ Do meu ponto de vista, com base no modelo do Sistema Único de Assistência Social construído pelo Brasil a partir de 2005, entendo que falta para Cuba ainda uma discussão da especificidade da política de assistência social. Nas palavras de Sposati: "A defesa da especificidade/particularidade da assistência social supõe assentar bases na construção de uma nova cultura política, isto é, supõe agir na contramão do que está dado no campo político" (2004, p. 40, grifo nosso).
} 
Em Cuba, o Estado é o responsável pelo financiamento e aplica os recursos a partir da identificação das necessidades da população. Os serviços/benefícios prestados pela proteção social são financiados diretamente pelo Estado, diferentemente do regime de Segurança Social, que recebe recursos do Estado, mas também de entidades de trabalhadores e de trabalhadores, regulados em legislação tributária. Em Cuba, não há participação da iniciativa privada no financiamento da proteção social (BORTOLI; COUTO; TELES, 2015).

No modelo de proteção social para abrigamentos, conforme demonstrado em material produzido pelo Escritório Nacional de Estatísticas (ONE), denominado "Salud pública y asistencia social (2017 e 2018)", atualmente existem 420 unidades, dentre os quais: 143 denominados lares dos idosos, 247 casas de avós e 30 casas para pessoa com deficiência.

Ainda, para medir o grau de proteção social utilizado em Cuba, o Centro de Estudios de Población y Desarrolo, em material intitulado "Acerca de la medicinadelbienestar em Cuba", traz as seguintes características:

[...] el carácter eminentemente social del desarrollo para y por los individuos, resalta aspectos prioritarios como la participación y protección social y los derechos de las personas, en el entendido de la participación social, como acción colectiva hacia lasatisf acción de objetivos específicos, con una identidad colectivacon valores, intereses, y motivacion es identificados como comunes (Bango 1996 en Pág. 51, CEPAL, 2008); la protección social, como el financiamiento proveniente de la Seguridad y la Asistencia Social Ej. Pensiones por edad, invalidez y muerte, así como las prestaciones por insuficiencia de ingresos, $u$ otras formas de vulnerabilidad social y que asumen un comprometimiento colectivo de la sociedad, enfunción de mitigar sus efectos y, los derechos; como e jercicio ciudadano que incluye no solo los civiles, sociales y políticos, si no además, la participación con mayor igualdade nel intercambio comunicativo, enel consumo cultural, enel manejo de la información y e nel acceso a los espacios públicos [...] Participación social: Población asociada a organizaciones de masas y asociacion essocial es gubernamentales o no; Proporción de mujeres y hombres por categoría educacional y formade ten enciadelempleo, especial énfasis en la actividad por cuenta propia; participación de mujer e se nel parlamento y enla toma de decisiones como dirigentes a diferentes niveles, Proporción de lapoblación que participa enlas eleccionesdel parlamento; Participación socialde mujeres y hombres, en particular enel uso deltiempo (tareas del hogar y fuera del hogar, participación en la actividad productiva o de servicios, en la toma de decisiones, en las actividades sociales, entre otras). Protección social: Población beneficiada por la seguridad y asistencia social y por los programas sociales de labatalla de ideas que incluyenl a atención a niñossin amparo filial, discapacitados o personas que padecen enfermedades severas, auncuandoson de baja incidencia en la población, pero que pudieran estar en desventaja social, adultos mayores beneficiados por el Sistema de atención a la familia (SAF), entre otros (CUBA, 2009, p. 7).

O foco do governo cubano encontra-se nas aplicações destinadas à proteção social da assistência social e em outras políticas, com contribuições importantes, como a de 
previdência social, saúde, educação e entre outras, bem como pelo acesso que os indivíduos em situação de vulnerabilidade social têm a benefícios sociais pela renda insuficiente, incluindo a própria família nessa oferta pela análise a seguir:

\begin{abstract}
Encuanto a la economía familiar, para conocer y estudiar como opera la misma ensuvinculación como, productor/consumidor/beneficiario, con la actividad económica y otras actividades o relaciones de intercambio que generan ingresos y gastos, no obstante a sus limitaciones (distribución al interior de los hogares, subestimación de declaración, entre otras); se utilizanlos indicadores tradicionales para sumedición, adaptados al contexto cubano (dualidad monetaria, mercados existentes y otros), entre ellos (CUBA, 2009).
\end{abstract}

Nesse sentido, pelas mesmas análises de Franzoni (2005), podemos concluir que em Cuba existe uma tendência para práticas familiaristas, ou seja, existe a tendência de transferência de responsabilidade do Estado para a família.

\title{
Considerações Finais
}

Diante do questionamento inicial do trabalho, e com os dados disponíveis nos diversos canais de comunicação social, para o ano de 2018, Cuba destinou 65\% do seu orçamento de 2018 para as áreas de saúde pública e assistência social (27\%), educação (21\%) e seguridade social (17\%), pode-se observar que nesse país, a assistência social se apresenta como um direito disponível. Entretanto; ao definir usuários/beneficiários dos serviços e benefícios ofertados, percebe-se um recorte menos universalista, porém ao contrário do que existe em outros países, a pobreza não significa marginalidade.

Assim, em Cuba, percebem-se avanços na organização e execução das ações das políticas de assistência social refletindo na melhoria das condições de vida da população vulnerável. Entretanto, ainda são focalizadas na população em risco social, objetivando a minorar o quadro de ascendência da desigualdade social em virtude da crise sofrida pelo país no começo dos anos 90 (FROTA, 2012).

Por fim, dentre as descobertas nesse estudo, é possível identificar um investimento considerado para a realização da proteção social as famílias cubanas, porém um enorme desafio para universalizá-los e buscar a desfamiliarização, ou seja, é preciso que o Estado crie capacidades institucionais que abarquem todas as necessidades da população. Ainda é preciso que se crie indicadores claros para aferir quais os resultados se esperam da política de 
assistência social perante a proteção social de famílias, e quais as condições objetivas para a realização desse trabalho (SPOSATI, 2012).

\section{Referências}

ÁLVAREZ GARCÍA, Anícia; CRUZ Anaya Betsy. La política social cubana: derrame haciaotrasregionesdel mundo. In: CONGRESS OF THE LATIN AMERICAN STUDIES ASSOCIATION, 28., Rio de Janeiro. Anales [...]. Pittsburgh: University of Pittsburgh, 2009.

ARCE, Maria Josefina. Zelar pelos idosos: prioridade do governo cubano. Editado por Maite González Martínez. Radio Havana Cuba, 25 jul. 2017. Disponível em http://www.radiohc.cu/pt/especiales/comentarios/136489-zelar-pelos-idosos-prioridadedo-governo-cubano. Acesso em 23/4/2018.

BORTOLI, Mari Aparecida; COUTO, Berenice Rojas; TELES, Heloísa. Assistência Social no Brasil, Cuba e Chile. In: Encontro Internacional de Política Social, 3.; Encontro Nacional de Política Social, 10., 2015, Vitória. Anais [...]. Vitória: UFES, 2015.

CARRARO, Gisele. As políticas sociais de assistência social, educação e saúde no Brasil e em Cuba: as particularidades dos processos de planejamento, monitoramento e avaliação. 2016. 251f. Tese (Doutorado em Serviço Social) - Pontifícia Universidade Católica do Rio Grande do Sul, Porto Alegre, 2016.

CARRO, Silvinia María. A assistência social no universo da proteção social - Brasil, França, Argentina. 2008. 253f. Tese (Doutorado em Serviço Social) - Programa de Pós Graduação em Serviço Social, Doutorado, da Pontifícia Universidade Católica de São Paulo, São Paulo.

CASTEL, Robert. A insegurança social: o que é ser protegido? Petrópolis: Vozes, 2005.

CÉSAR, Maria Auxiliadora. Mulher e política social em Cuba: o contraponto socialista ao bemestar capitalista. Brasília, DF: Edições Alva, 2005.

CUBA. Constituición de la Republica de Cuba. 1992. Disponível em: https://www.acnur.org/fileadmin/Documentos/BDL/2001/0511.pdf. Acesso em: 23 abr. 2018.

CUBA. Ministerio de Justicia. Ley no 105/08. Regulaento de laLey de Seguridad Social. Gaceta Oficial, La Habana, n. 4, p. 15, 22 enero 2009.

ESPING-ANDERSEN, Gosta. O futuro do Welfare State na Nova Ordem Mundial. Lua Nova, São Paulo, n. 35, p. 73-111, 1995.

FLEURY, Sônia. Estado sem cidadãos: seguridade social na América Latina. Rio de Janeiro: Editora Fiocruz,1994. 252 p. Disponível em: http://https://static.scielo.org/scielobooks/jm5wd/pdf/ fleury-9788575412428.pdf. Acesso em: 23 abr. 2018. 
FRANZONI, Juliana Martínez. Regimenes de bien estar en América Latina: consideraciones generales e itinerários regionales. Revista Centro-Americano de Ciências Sociales, [S.I.] v. II, n. 2, p. 41-77, dic. 2005.

FROTA, Mainara Mizzi Rocha. Políticas sociais no capitalismo e no socialismo: uma análise comparativa entre brasil e Cuba. 2012. Dissertação (Mestrado em Sociologia) - Universidade Federal do Recôncavo da Bahia, Salvador, 2012.

GANEV, Eliane. Políticas Sociais na perspectiva socialista, a partir da experiência cubana. Revista Praia Vermelha, São Paulo, v. 3, n. 2, 2013. Disponível em:

https://revistas.ufrj.br/index.php/praiavermelha/article/view/3595. Acesso em: 10 abr. 2018.

HARNECKER, Marta. Cuba: democracia ou ditadura? São Paulo: Global Editora e Distribuidora Ltda, 1997.

INDEX MUNDI. Produto Interno Bruto (PIB) per capita. 2019. Disponível em: https://www.indexmundi.com/pt/cuba/produto_interno_bruto_(pib)_per_capita.html. Acesso em: 15 maio 2018.

LECHNER, Norbert. Estado, mercado e desenvolvimento na América Latina. Lua Nova: Revista de Cultura e Política, São Paulo, n. 28/29, p. 237-248, 1993. Doi: 10.1590/S010264451993000100011

MESA-LAGO, Carmelo. A economia cubana no início do século XXI: avaliação do desempenho e debate sobre o futuro. Opinião Pública, Campinas, v. 9, n. 1, p. 190-223, 2003. Disponível em: http://www.scielo.br/pdf/op/v9n1/16157.pdf. Acesso em: 15 maio 2018.

ONE - OFICINA NACIONAL DE ESTADÍSTICAS. Anuário estadístico de Cuba 1997. Havana: ONE, 1999.

NE - OFICINA NACIONAL DE ESTADÍSTICAS. Salud pública y asistencia social. Ministro de Salud Pública y Asistencia Social, 2017. Disponível em: < https://www.mspas.gob.gt/images/files/acercadelmspas/MemoriadeLabores2017.pdf >. Acesso em: 19, outubro e 2020.

PNUD - PROGRAMA DAS NAÇÕES UNIDAS PARA O DESENVOLVIMENTO. Relatório de Desenvolvimento humano 2010. New York: PNUD, 2010. Disponível em: http://hdr.undp.org/en/media/HDR_2010_PT_Chapter5_reprint.pdf. Acesso em: 19 fev. 2019.

SEGURID SOCIAL PARA TODOS. Disponível em: http://www.seguridadsocialparatodos.org/aysss/index.html. Acesso em: 15 maio 2018.

SPOSATI, Aldaíza Oliveira. Especificidade e intersetorialidade da Política de Assistência Social. Serviço Social \& Sociedade, São Paulo, n. 77, 2004.

SPOSATI, Aldaíza Oliveira. Proteção social e família: um desafio para a política pública de assistência social. Revista do Fórum Nacional de Secretários(as) de Estado de Assistência Social, Brasília, v. I, 2012. 
SPOSATI, Aldaíza Oliveira. Proteção social e seguridade social no Brasil: pautas para o trabalho do assistente social. Serviço Social \& Sociedade, São Paulo, n. 116, p. 652-674, out./dez. 2013.

SPOSATI, Aldaíza Oliveira. Proteção Social na América Latina em contexto da globalização. Debates Sociais, Rio de Janeiro, ano XLIII, n. 69/70, p. 59-86, 2008.

SPOSATI, Aldaíza Oliveira. Regulação social tardia: características das políticas sociais latinoamericanas na passagem entre o segundo e o terceiro milênio. Caderno Ideação, Porto Alegre, p. 33- 53, 2002.

SPOSATI, Aldaíza Oliveira. Tendências latino-americanas da política social pública no século 21. Revista Katálysis, Florianópolis, v. 14, n. 1, p. 104-115, jan. 2011. Disponível em: https://periodicos.ufsc.br/index.php/katalysis/article/view/S1414-49802011000100013. Acesso em: 31 abr. 2018.

THE GLOBAL ECONOMY. Indicadores de Cuba. [2018]. Disponível em: https://pt.theglobaleconomy.com/Cuba/Unemployment_rate/. Acesso em: 16 abr. 2018.

WEHRLE, Beat. From welfare to workfare: a modernização da hegemonia capitalista: Análise da Assistência Social na Suíça. 2011. Dissertação (Dissertação em Serviço Social) - Pontifica Universidade Católica de São Paulo, São Paulo, 2011. 